\title{
Effect of pH on Mycelial Growth and Sporulation of Postharvest Pathogen Colletotrichum gloeosporioides (Penz.) Penz \& Sacc. and Pestalotiopsis mangiferae ( Henn.) Steyaert
}

\author{
Niren Majumdar* and Nakul Chandra Mandal
}

Dept. of Plant Protection, Palli-Siksha Bhavana (Institute of Agriculture), Visva-Bharati, Sriniketan, Birbhum, West Bengal (731 236), India

\section{Corresponding Author}

Niren Majumdar

e-mail: niren_majumder@yahoo.com

\author{
Article History \\ Article ID: AR1874 \\ Received in 04 ${ }^{\text {th }}$ May, 2018 \\ Received in revised form $19^{\text {th }}$ May, 2018 \\ Accepted in final form $29^{\text {th }}$ May, 2018
}

\begin{abstract}
Among the plethora of postharvest pathogens causing enormous losses Colletotrichum gloeosporioides is an important polyphagous pathogen, Pestalotiopsis mangiferae is monophagus to mango. A study was conducted with these two pathogens obtained from banana and mango to find out the optimum $\mathrm{pH}$ level for growth and sporulation as well as the possible utilization of this knowledge in developing management strategy of quiescent infections by them. Both fungi grew at Potato Dextrose Broth and PDA within the pH regime 4.0-9.0 tested at $28 \pm 1{ }^{\circ} \mathrm{C}$, although growth rate differs significantly at different hours of incubation. The optimum pH for growth and sporulation differs significantly. The optimum $\mathrm{pH}$ for both growth and sporulation was $5.0 \mathrm{in} \mathrm{PDA}$. In case of potato dextrose broth pH 6.0 was optimum for $C$. gloeosporioides and $P$. mangiferae has wide adaptability within ph range 4.0-6.0. Both pathogens sporulate in all the $\mathrm{pH}$ regime 4.0-9.0, however $C$. gloeosporioides best sporulate at $\mathrm{pH} 5.0$ and $\mathrm{P}$. mangiferae at pH.8.0 The role of pH modulated host resistance has been discussed.
\end{abstract}

Keywords: Colletotrichum gloeosporioides, Pestalotiopsis mangiferae, $\mathrm{pH}$, fungal growth, mycelia, sporulation

\section{Introduction}

Fruits and vegetables are susceptible to various postharvest diseases during transit; market and storage caused by various biotic and abiotic factors, thus ultimately reduce the quality and quantity. Banana and mango are two most preferred tropical fruits all over the world, many European countries import them. Among many pathogens, Colletotrichum gloeosporioides infects both banana and mango whereas Pestalotiopsis mangiferae is restricted to only on mango affecting fruits (preharvest and postharvest stage) and leaf. These two fungal pathogens, Colletotrichum gloeosporioides and Pestalotiopsis mangiferae remain quiescent in the young stage at field (Swinburne, 1983) and on maturity of the fruit infection progresses and causes exhaustive damage and loss. Differential varietal behaviour of mango in terms of susceptibility to $C$. gloeosporioides both at preand postharvest stage under Indian condition have been documented (Srivastva,1965; Tandon and Singh, 1969; Dasgupta and Mandal, 1989). Fruits undergo several changes including $\mathrm{pH}$ between growth and development of young stage and subsequently maturity in the late phase just before harvest (Dasgupta and Mandal, 1989). In mosambi infected with C. gloeosporioides, acidity of the fruit was enhanced. Similarly, in vegetables $\mathrm{pH}$ is also known to be linked with host resistance factor as in Tomato-Alternaria system (Swinburne, 1983). The quiescence to necrotrophy has been explained in the light of genetic control of $\mathrm{pH}$ regulation. Fungal toxic products are capable to terminate biotrophic phase towards preparation to undergo subsequent necrotrophic growth. Although the fungal $\mathrm{pH}$ modulation is host induced yet the specific virulence factors of pathogen is dictated/ modulated in the environment (Alkan et al., 2013, Prusky et al., 2013).

Various parameters influence greatly to fungal morphology, physiology and pathogenicity. Among them temperature, $\mathrm{pH}$, humidity, light etc. are factors, which influence their growth and sporulation of field fungi.The work have been extensively studied and compiled by Cochrane (1958); Griffin (1981) and still vigorously continued in different parts of the world. In vitro study of these factors on fungi may be helpful for various strategy developments on management particularly toxicogenic fungi (Pardo et al., 2006). 'Negative Hydrogen ion concentration' $(\mathrm{pH})$ of the medium either directly by its action on the cell surfaces or indirectly by its effect on the availability of nutrients affects growth dynamics. Most fungi have optimum $\mathrm{pH}$ around 5.0 within a range of 3.0 to 8.0. 
Published reports from different authors indicate that there are variations in optimum $\mathrm{pH}$ for dry mycelial weight and sporulation of fungi (Esteban et al., 2006; Khan et al., 2011) in most cases. In case of Colletotrichum gloeosporioides, the optima for growth and sporulation were $\mathrm{pH} 5.5$ and $\mathrm{pH}$ 6.5, respectively (Deshmukh et al., 2012). But Pandy et al. (2012) recorded both growth and sporulation at $\mathrm{pH}$ 6.0. Present isolate of $C$. gloeosporioides may behave differently due to geographical isolation and relevant studies in respect of Pestalotiopsis mangiferae is lacking Therefore the research has been conducted. Therefore, give your justification to conduct the research.

\section{Materials and Methods}

The invitro experiments were carried out in Plant Protection department of Palli Siksha Bhavana, Sriniketan, West Bengal, India during 2017.

\subsection{Isolation and identification of fungi}

Naturally infected ripe banana and mango fruits were collected from local Bolpur market $\left(23.6686^{\circ} \mathrm{N}, 87.6827^{\circ} \mathrm{E}\right)$ and Palli Siksha Bhavana orchard $\left(23.6693^{\circ} \mathrm{N}, 87.6593^{\circ} \mathrm{E}\right)$. Isolation of fungi was performed by standard surface sterilization method followed by incubation on PDA at $25 \pm 1{ }^{\circ} \mathrm{C}$ for $24-48 \mathrm{hrs}$. The fungal colonies that appeared on the PDA surface surrounding fruit bits after incubation period were aseptically transferred on fresh sterilized petri plates containing PDA. Isolate from a single colony were maintained for further studies including identification with the help of standard literature.

\subsection{Preparation of potato dextrose broth and pda media of} varying ph levels

Potato dextrose broth (PDB) was prepared by standard method and in order to avoid bacterial contamination $0.05 \mathrm{~g}$ of chloramphenicol $\mathrm{l}^{-1}$ were added to the medium after sterilization. The prepared unsterilized medium was distributed within $100 \mathrm{ml}$ conical flasks at the rate of 50 $\mathrm{ml}$ flask $^{-1}$. The required $\mathrm{pH}$ was adjusted either by adding Hydrochloric acid $(0.1 \mathrm{~N} \mathrm{HCl})$ or Sodium hydroxide $(0.1 \mathrm{~N}$ $\mathrm{NaOH}$ ) solution. In order to stabilize the $\mathrm{pH}, 20 \%$ phosphate buffer was used. Six pH treatment levels 4.0, 5.0, 6.0, 7.0, 8.0, and 9.0 were maintained and replicated thrice. Two percent agar was added for solidification of PD broth to PDA medium. The final $\mathrm{pH}$ was measured using electrical $\mathrm{pH}$ meter before sterilization within autoclave at $121^{\circ} \mathrm{C}$. Prepared media was immediately used for growth studies of both fungi.

2.3. Inoculation and mycelial development of c. gloeosporioides and $p$. mangiferae in the broth media

A disc ( $5 \mathrm{~mm}$ diameter) of the culture of test pathogens was transferred into each flask aseptically. The inoculated flasks were incubated within BOD for 10 days at $28 \pm 1^{\circ} \mathrm{C}$. The culture media alongwith mycelia growth were separately decanted from each flask and filtered using pre-weighted Whatman filter paper No. 1 to recover the mycelia after washing several times with distilled water. The mycelia were oven dried at 60 ${ }^{\circ} \mathrm{C}$ until constant dry weight was attained. The dried mycelia were weighed $(\mathrm{g})$ using electronic balance. The solidified PDA medium within petri dishes was inoculated at the centre by a disc ( $5 \mathrm{~mm}$ diameter) of the culture of test pathogens. The average of the triplicates for these two experiments was recorded.

\subsection{Inoculation and sporulation of C. gloeosporioides and P. mangiferae in the agar media}

Five $\mathrm{mm}$ discs of the culture of $C$. gloeosporioides and $P$. mangiferae were obtained from the growing edges of PDA cultured colonies using sterilized cork borer. The agar plugs were transferred to the centre of PDA plates (one plug per plate) at different $\mathrm{pH}$ levels and incubated at temperature of approximately $28 \pm 1^{\circ} \mathrm{C}$ for six (6) days. Each treatment was in triplicate. The spores in each treated Petri dish was washed in $50 \mathrm{ml}$ ( $25 \mathrm{ml}+25 \mathrm{ml}$ ) sterilized distilled water by using of sterile slide and rubbed on the surface of mycelia growth on media to dislodge the spores and poured into beaker. $0.2 \mathrm{ml}$ drop of this solution was placed in the haemocytometer and mounted for counting on compound light microscope. Each treatment was in triplicate. The number of spore $\mathrm{ml}^{-1}$ was computed.

\subsection{Statistical analysis}

Data obtained were analysed using one way analysis of variance (ANOVA) using SPAR 3.0 for data analysis.

\section{Results and Discussion}

Although the teleomorph state of $C$. gloeosporioides and $P$. mangiferae taxonomically belong to the same class sordariomycetes (Division:Ascomycota) but they differ at family level Glomerellaceae and Sporocadaceae, respectively, yet ascopores production is more common in the former one. In the anamorph state too both produce conidia of different shape (pigmented conidia in Pestalotiosis and hyaline in Colletotrichum) within acervuli for enormous sporulation alongwith deep blue glutinous substances for the first one and light salmon/orange for latter. The pathogenic behaviour particularly symptoms development and ecological niche of them is entirely different in spite of both genera are polyphagous in nature (Lee et al., 2003). P. mangiferae is a monophagous pathogen. Despite the genetic control mechanism, the nutritional uptake and balance perhaps play significant roles in the growth behaviour and dynamics as well as kind and quantity of spore production (Bailey and Jegar, 1992).

\subsection{Effect of different ph levels on radial growth and mycellial dry weight}

It is revealed from results presented in Table 1 and 2 and Figure 1 and 2 both $C$. gloeosporioides and $P$. mangiferae radially grew in the tested $\mathrm{pH}$ ranges of $4-9$, but growth rate differs significantly at different hours of incubation. Radial growth became faster in C. gloeosporioides as compared to 


\begin{tabular}{l}
$\begin{array}{l}\text { Table 1: Radial growth of Colletotrichum gloeosporioides in } \\
\text { different } \mathrm{pH} \text { and incubation time }\end{array}$ \\
\hline $\mathrm{pH}$ \\
\cline { 2 - 8 } \\
\cline { 2 - 8 }
\end{tabular}

*Average of three replicates

Table 2: Radial Growth of Pestalotiopsis mangiferae in different $\mathrm{pH}$ and incubation time*

\begin{tabular}{|c|c|c|c|c|c|c|}
\hline \multirow[t]{2}{*}{$\mathrm{pH}$} & \multicolumn{6}{|c|}{$\begin{array}{c}\text { Radial growth ( } \mathrm{mm} \text { ) after different hours } \\
\text { of incubation }\end{array}$} \\
\hline & 24 & 48 & 72 & 96 & 120 & 144 \\
\hline 4.0 & 8.50 & 23.67 & 39.67 & 52.33 & 65.67 & 78.17 \\
\hline 5.0 & 8.17 & 24.67 & 44.67 & 59.17 & 73.00 & 84.67 \\
\hline 6.0 & 8.67 & 22.50 & 41.17 & 54.83 & 68.33 & 84.00 \\
\hline 7.0 & 9.00 & 22.50 & 40.33 & 49.00 & 57.67 & 72.00 \\
\hline 8.0 & 7.50 & 20.33 & 39.50 & 50.00 & 62.67 & 79.33 \\
\hline 9.0 & 7.17 & 16.67 & 35.83 & 46.00 & 54.67 & 67.83 \\
\hline SEm \pm & 0.24 & 0.89 & 0.33 & 0.75 & 2.21 & 3.26 \\
\hline$C D(p=0.05)$ & 0.73 & 2.75 & 1.01 & 2.30 & 6.80 & 10.03 \\
\hline
\end{tabular}

*Average of three replicates

Growth rate hour ${ }^{-1}$ of $C$. gloeosporioides

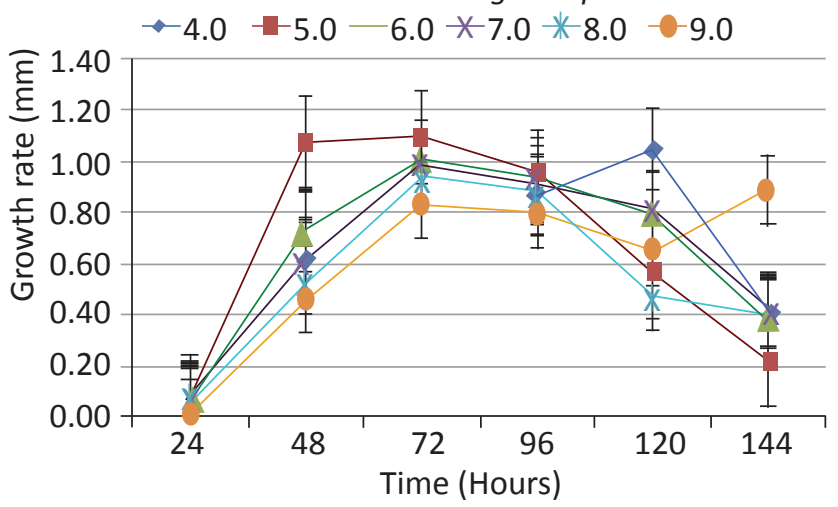

Figure 1: Growth rate of $C$. gloeosporioides in different $\mathrm{pH}$ level $\left(\mathrm{hr}^{-1}\right)$

P. mangiferae although up to $72 \mathrm{hrs}$ of incubation growth rate of P.mangiferae was higher. The highest growth was obtained at $\mathrm{pH} 5.0$ for both $C$. gloeosporioides and P. mangiferae.

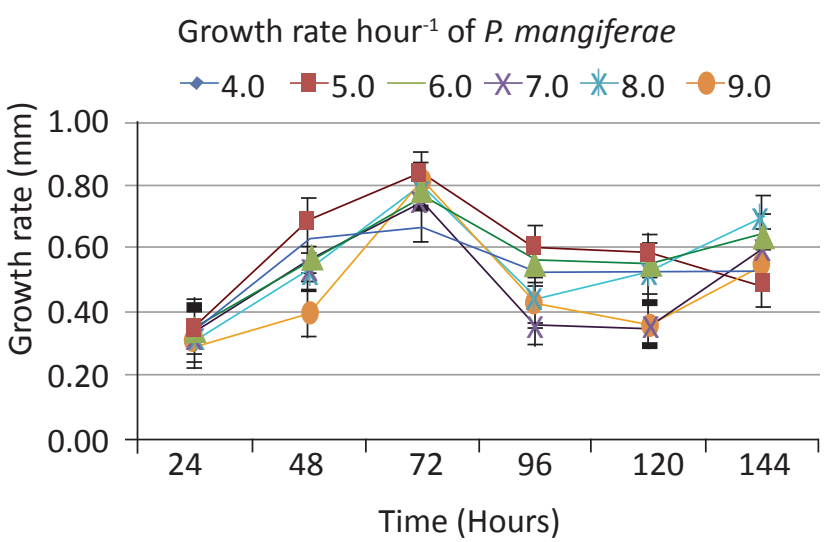

Figure 2: Growth rate of $P$. mangiferae in different $\mathrm{pH}$ level $\left(\mathrm{hr}^{-1}\right)$

Griffin (1981) although opined that pH probably have little effect on growth of fungi rather than components of the medium, but this study indicates otherwise as fresh medium prepared was utilized for the study thus avoiding the variation in components and composition. The genetic makeup of these two fungi seems responsible for uptake behaviour of nutrients which ultimately has been reflected in variation of growth rate. At higher $\mathrm{pH}$ of 9.0 the uptake of nutrients seems to be partially impaired which may draw attention of future researchers. Earlier, many researchers have pointed out that most fungi can generally tolerate acidic $\mathrm{pH}$ than alkaline condition (Lilly and Barnett, 1951). Excellent growth of various isolates of $C$. gloeosporioides obtained from chrysanthemum, turmeric and chilli were recorded at pH 5.5 to 6.0. (Naik et al., 1988; Thakare and Patil, 1995; Patel, 2000; Prashanti and Kulkarni, 2003; Patel, 2004). Under in vitro condition the growth dynamics of certain species of foliicolous Pestalotiopsis has been found to differ after 5 days of incubation at $25^{\circ} \mathrm{C}$ with different $\mathrm{pH}$ levels. These fungi grew at $\mathrm{pH}$ range of 4.5-7.0 with an optimum growth at $\mathrm{pH} 7.0$. The conspicuous decline in growth occurred at an increase $\mathrm{pH}$ from 7.5-9.0. In contrast to our finding, in Libya three species of Pestalotiopsis did not grow at $\mathrm{pH}$ 4.0. These isolates required 5 days to reach maximum growth where as our isolate reached in 3 days and after words start decline (El-Gali, 2017).

Data presented in Table 3 indicate that both fungi grew in all $\mathrm{pH}$ ranges (4.0-9.0) tested, however, maximum dry weight of mycelia in C. gloeosporioides was obtained at $\mathrm{pH} 6.0$ followed by pH 7.0. (Deshmukh et al., 2012; Kumara and Rawal, 2008) The higher CD value for Pestalotiopsis mangiferae indicates there was no significant variation in dry weight of mycelia when cultured at $\mathrm{pH} 8.0$ and 9.0 tested. The highest radial growth for $P$. mangiferae was at $\mathrm{pH} 5.0$ followed by $\mathrm{pH} 6.0$. Either the much precision becomes apparent or the organism has the capacity to overcome the impact of $\mathrm{pH}$ under liquid culture technique.

3.2. Effect of different ph levels on sporulation of $C$. gloeosporioides and P. mangiferae

The study of sporulation of many fungi under in vitro condition 
Table 3: Mycelial dry weight of two quiescent pathogens of mango after 240 hrs of incubation

\begin{tabular}{lcc}
\hline $\mathrm{pH}$ & $\begin{array}{c}\text { Colletotrichum } \\
\text { gloeosporioides }\end{array}$ & $\begin{array}{c}\text { Pestalotiopsis } \\
\text { mangiferae }\end{array}$ \\
\hline 4.0 & 126.00 & 527.00 \\
5.0 & 132.67 & 530.33 \\
6.0 & 238.33 & 553.33 \\
7.0 & 206.67 & 498.33 \\
8.0 & 136.33 & 424.33 \\
9.0 & 91.667 & 344.33 \\
$\mathrm{SEm} \pm$ & 9.2155 & 42.566 \\
$\mathrm{CD}(p=0.05)$ & 28.396 & 131.16 \\
\hline
\end{tabular}

was a matter of interest among many researchers of the past. In C. gloeosporioides maximum sporulation was obtained in $\mathrm{pH} 5.0$ followed by $\mathrm{pH} 9.0$ and $\mathrm{pH}$ 7.0. On the other hand the highest sporulation for $P$. mangiferae was recorded in pH 8.0 followed by pH 5.0 and pH 4 (Table 4). Kumara and Rawal (2008) reported that $\mathrm{pH} 5.0$ was suitable for mycelia growth while $\mathrm{pH} 6.0$ preferred for the sporulation of $C$. gloeosporioides. Exellent sporulation of $C$. gloeosporioides was recorded by Deshmukh et al. (2012) at pH 5.0 to 6.0. Similar observation recorded by Thakare and Patil (1995); Prashanti and Kulkarni (2003).

Table 4: Sporulation of Colletotrichum gloeosporioides and Pestalotiopsis mangiferae under in vitro condition

\begin{tabular}{lcc}
\hline $\mathrm{pH}$ & \multicolumn{2}{c}{ Spore concentrations $\mathrm{m}^{-1}\left(\times 10^{6}\right)$} \\
\cline { 2 - 3 } & $\begin{array}{c}\text { Colletotrichum } \\
\text { gloeosporioides }\end{array}$ & $\begin{array}{c}\text { Pestalotiopsis } \\
\text { mangiferae }\end{array}$ \\
\hline 4.0 & $17.99^{\mathrm{b}}$ Low & $2.44^{\mathrm{bc}}$ \\
5.0 & $33.30^{\mathrm{a}}$ High & $2.78^{\mathrm{b}}$ \\
6.0 & $19.44^{\mathrm{b}}$ Low & $1.89^{\text {cd }}$ \\
7.0 & $27.98^{\mathrm{a}} \mathrm{High}$ & $1.63^{\mathrm{d}}$ \\
8.0 & $18.35^{\mathrm{b}}$ Low & $4.05^{\mathrm{a}}$ \\
9.0 & $31.39^{\mathrm{a}} \mathrm{High}$ & $0.88^{\mathrm{e}}$ \\
$\mathrm{SEm} \pm$ & 1.89 & 0.25 \\
$\mathrm{CD}(p=0.05)$ & 5.60 & 0.73 \\
\hline
\end{tabular}

If we compare the growth and sporulation it is clear that (Figure 1) C. gloeosporioides in $\mathrm{pH} 5.0$ had maximum mycelia growth and sporulation but $\mathrm{pH} 4.0$ and 6.0 had more mycelia growth as compared to sporulation. Since growth and sporulation are independent phenomenon, the impact of growth on sporulation seems insignificant although in P. mangiferae $\mathrm{pH} 6.0$ had less mycelial growth with more sporulation. Since the $\mathrm{pH}$ has expected relations with growth and sporulation of fungi, a study was undertaken to define the nature of relationship by simple correlation studies and the parameter of same is correlation coefficient ( $r)$. The relationship between $\mathrm{pH}$ and growth of $\mathrm{C}$. gloeosporioides is extremely negative ( $r=-0.91)$ and the highly negative for $P$. mangiferae ( $r=-0.76)$ at 120 hours of incubation. Interestingly, the relationship between $\mathrm{pH}$ and sporulation was slightly positive for $C$. gloeosporioides ( $r=0.24$ ) but slightly negative for $P$. mangiferae $(r=-0.21)$. This may be possible because of the inherent variation in the method of spore formation between these two fungi.

In Diplocarpon mali, Zhao et al. (2010) recorded optimum $\mathrm{pH}$ 5.0-7.0 for mycelia growth and pH 5.0-8.0 for conidial production.

\section{Conclusion}

The $\mathrm{pH}$ requirement of growth and sporulation differs between the two fungi $C$. gloeosporioides and $P$. mangiferae and sporulation may be the effect of higher $\mathrm{pH}$ shock in $P$. mangiferae. The optimum $\mathrm{pH}$ can be used for any further culture. The synthesis and continued presence of preinfectional chemical compounds within young green fruits of many crops have been found to be modulated with changing $\mathrm{pH}$ along with the fruit age and progression of maturity. This study partially lends supports to the mechanism of quiescence and subsequent infection at maturity.

\section{References}

Alkan, N., Espeso, E.A., Prusky, D., 2013. Virulence regulation of phytopathogenic fungi by $\mathrm{pH}$. Antioxid Redox Signal 19, 1012-1025.

Bailey, J.A., Jeger, M.J., 1992. Colletotrichum:Biology, Pathology and Control. CAB International, 62.

Cochrane, V.W., 1958. Physiology of fungi. John Wiley \& Sons Inc., 21.

Dasgupta, M.K., Mandal, N.C., 1989. Postharvest pathology of perishables. Oxford and IBH Publ. Co. Pvt. Ltd. New Delhi, 623.

Deshmukh, A.J., Mehta, B.P., Sabalpara, A.N., Patil, V.A., 2012. In vitro effect of various nitrogen, carbon sources and $\mathrm{pH}$ regimes on the growth and sporulation of Colletotrichum Penz. and Sacc causing anthracnose of Indian bean. Journal of Biopesticides 5, 46-49.

El-Gali, Z.I., 2017. Effect of some ecological factors on growth of Pestalotiopsis spp. Isolated from mastic shrubs leaves. Journal of Advanced Botany and Zoology 5(3), 1-5.

Esteban, A., Abarca, M.L., Bragulat, M.R., Cabanes, F.J., 2006. Effect of $\mathrm{pH}$ on ochratoxin a production by Aspergillus niger aggregate species. Food Additives and Contaminants 23, 616-622.

Griffin, D.H., 1981. Fungal Physiology. John Wiley \& Sons, 383. Khan, I.H.S., Saifulla, M., Mahesh, S.B., Pallavi, M.S., 2011 Effect of different media and environmental conditions on the growth of Fusarium oxysporum f. sp. ciceri causing fusarium wilt of chickpea. International Journal of Science and Nature 2(2), 402-404. 
Kumara, K.L.W., Rawal, R.D., 2008. Influence of carbon, nitrogen, temperature and $\mathrm{pH}$ on the growth and sporulation of some Indian isolates of $C$. gloeosporioides causing anthracnose disease of papaya (Carica papaya L.). Tropical Agricultural Research and Extension 11, 7-12.

Lee N, D'Souza, C.A., Kronstad, J.W., 2003. Of smuts, blasts, mil dews, and blights: CAMP signaling in phytopathogenic fungi. Annual Review of Phytopathology 41, 399-427.

Lilly, V.G., Barnett, H.L., 1951. Physiology of Fungi. McGraw Hill Book Company Inc., New York, 464.

Naik, M.K., Hiremath, P.C., Hegde, R.K., 1988. Physiological and nutritional studies on Colletotrichum gloeosporioides, A causal agent of anthracnose of beetlevine, Mysore Journal of Agricultural Sciences 22, 471-474.

Pandey, A., Yadava, L.P., Manoharan, M., Chauhan, U.K., Pandey, B.K., 2012. Effectiveness of cultural parameters on the growth and sporulation of colletotrichum gloeosporioides causing anthracnose disease of mango (Mangifera indica L.) On Line Journal of Biological Sciences 12(4), 123-133.

Pardo, E., Marln, S., Ramos, A.J., Sanchis, V., 2006. Ecophysiology of ochratoxigenic Aspergillus ochraceus and Penicillium verrucosum isolates. Predictive models for fungal spoilage prevention-a review 23(4), 398-410.

Prashanthi, S.K., Kulkarni, S., 2003. Effect of different temperature and $\mathrm{pH}$ levels on mycoherbicides of eupatorium (Chromaloena odorata (L) K \& R) weed. Plant Pathology Newsletter 21, 9-11.

Prusky, D., Barad, S., Luria, N., Ment, D., 2014. Chapter II: $\mathrm{pH}$ Modulation of Host Environment, a Mechanism Modulating Fungal Attack in Postharvest Pathogen Interactions. In: Prusky, D., Gullino, M.L. (Eds.), Postharvest Pathology: Plant Pathology in the $21^{\text {st }}$ Century, Springer, Berlin, 137.

Srivastava, O.P., 1968. Soft rot of deshi mango fruit and the pathogenicity of the isolated micro-organism. Journal of Indian Botanical Society 47, 328-329.

Swinburne, T.R., 1983. Quiescent infection in postharvest disease. In: Dennis, C. (Ed.), Postharvest Pathology of Fruits and Vegetables, London Academic press, 1-12.

Tandon, I.N., Singh, B.B., 1969. Studies on anthracnose of guava and its control. Indian Phytopathol 22, 322-326.

Thakare, C.S., Patil, P.Y., 1995. Studies of leaf blight of chrysanthemum caused by Colletotrichum gloeosporioides. Journal of Maharashtra Agricultural University 20(1), 49-52.

Zhao, H., Huang, L., Xiao, C.L., Liu, J., Wei, J., Gao, X., 2010. Influence of culture media and environmental factors on mycelial growth and conidial production of Diplocarpon mali. The Society for Applied Microbiology, Letters in Applied Microbiology 50, 639-644. 